\title{
Development of a Heat Sink Module for a Near-Term DEMO Divertor
}

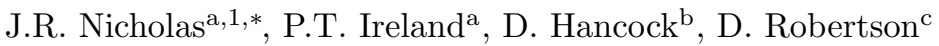 \\ ${ }^{a}$ Osney Thermofluids Institute, Southwell Building, University of Oxford, Department of Engineering Science, Osney Mead, Oxfordshire, \\ OX2 OES, United Kingdon \\ ${ }^{b}$ Culham Centre for Fusion Energy, Culham Science Centre, Abingdon, Oxfordshire, OX14 3DB, United Kingdom \\ ${ }^{c}$ Rolls-Royce Plc., Atlantic House, PO Box 2000, Derby, Derbyshire, DE21 7XX, United Kingdom
}

\begin{abstract}
A heat sink module has been developed for high-heat flux applications in the divertor region of a near term DEMO divertor. The concept employs water jet impingement, in a cascading flow path, together with $\mathrm{CuCrZr}$ as the structural material. This fluid-flow architecture maximises the heat transfer coefficient obtained for a given coolant flow rate. Combined with high operational pressures, it facilitates increased coolant outlet temperatures. A conjugate CFD study was performed to compare its performance to the ITER divertor under a representative heat flux boundary condition of $10 \mathrm{MW} / \mathrm{m}^{2}$. A transient thermochromic liquid crystal technique was used to experimentally validate the CFD heat transfer data, using air as the working fluid at matched Reynolds numbers. These results showed that area averaged heat transfer coefficients could be accurately predicted by the CFD to within $\sim 12 \%$.
\end{abstract}

Keywords:

divertor, heat sink, cooling, high-heat flux

\section{Introduction}

Designing components to handle the heat flow boundary conditions predicted in the divertor region of a near term DEMO presents a unique challenge. Localised steadystate heat fluxes are expected to be in the region of 10-15 $\mathrm{MW} / \mathrm{m}^{2}$ [1-4, whilst transient events can lead to heat loads of $20 \mathrm{MW} / \mathrm{m}^{2}$ to $1 \mathrm{GW} / \mathrm{m}^{2}$, 4, 5]. Neutron fluence levels in a DEMO will also be considerably higher than those in ITER, which presents additional challenges in material selection.

A large number of concepts have been proposed to date as a solution to divertor cooling [6-15]. They can broadly be split into two categories: low temperature copper alloy designs, and high temperature tungsten alloy concepts. The former of these often use water as the coolant, whilst the latter either employ a gas, molten salt or liquid metal. Helium is often the preferred option for high temperature gaseous cooling due to its chemical inertness and good heat transfer characteristics. Current experience with active cooling in research machines has focused around the low temperature copper alloy designs, which has been the category selected for ITER.

\footnotetext{
${ }^{*}$ Corresponding author

Email addresses: jack.nicholas@eng.ox.ac.uk (J.R. Nicholas), peter.ireland@eng.ox.ac.uk (P.T. Ireland), David.Hancock@ccfe.ac.uk (D. Hancock), Daniel.Robertson@Rolls-Royce.com (D. Robertson)
}

Current high-heat flux (HHF) cooling proposals for a DEMO divertor, employing a water coolant, involve the extrapolation of existing design concepts 6, 16, 17. To achieve acceptable peak structural temperatures these tubular systems require high mass flow rates. This limits both the temperature change of the coolant through the divertor cassette - limiting plant thermal efficiency - and the heat flux handling capacity. To address these challenges any new water-based DEMO HHF module should aim to achieve the following, relative to current ITER-like proposals:

(1) A reduction in the mass flow rate required to obtain a set component temperature; at a given heat flux;

(2) An increase in the operational pressure to ensure higher fluid temperatures can be achieved without the risk of a phase change; above the critical heat flux this can lead to a catastrophic increase in the wall temperature.

Point (1) is a practical statement of the requirement for enhancing heat transfer. In divertor HHF systems this involves considering both conduction and convection, as Biot numbers are generally of the order of $10^{-1}$. The convective resistance is minimised when the product of the area averaged heat transfer coefficient and the internal wetted area is maximised. For a given material, conductive resistance is minimised by using short conduction paths lengths and avoiding geometric heat flux peaking.

Water coolant circuits at pressures in excess of 150 bar 
are routinely used in fossil fuel power stations. These pressures are also frequently encountered in the oil and gas extraction sectors. This latter industry has developed Printed Circuit Heat Exchangers (PCHEs) that are able to operate at working fluid pressures and temperatures of 600 bar and $900^{\circ} \mathrm{C}$ respectively 18 . The application of high pressure technologies developed in these two sectors offers a potential route to fulfilling aim (2).

\section{A High-Heat Flux Heat Sink Module}

In gas turbines, jet impingement is used to combat the most extreme heat loads at the leading edge of the turbine blade, where heat fluxes can be in excess of $3 \mathrm{MW} / \mathrm{m}^{2}$ 19. Convective heat transfer coefficients produced by this method are over three times those achievable in parallel wall flow concepts, at equivalent flow speeds 20]. Though considered for the HETS concept [10, 21, the majority of DEMO divertor proposals employing jet impingement are focused around the use of helium as a coolant [7, 10, 14] and tungsten as a structural material.

A novel means of reducing cross-flow when feeding multiple jets was developed for power electronic applications by 22]. It involves deploying the coolant in a cascade arrangement, whereby spent flow from one jet/array is used to feed another jet/array. A wall separates adjacent cascade elements, stopping the build-up of any cross-flow. This flow arrangement also offers a means of exchanging additional pressure drop in a system for a reduced mass flow rate. Such a configuration is particularly effective when the coolant is a liquid, as high pressures can be achieved for minimal pumping work.

To fulfil the aims set out in Sec 1 the authors decided to pursue a high pressure cooling system employing cascade jet impingement. Component manufacturing complexity was reduced by using a flat plate geometry. This also kept the heat conduction paths small, and has the potential to increase temperature uniformity relative to other designs. By stacking multiple sheets into a laminate structure, three dimensional flow paths can be incorporated into a compact design.

An hexagonal geometry was chosen for the in-plane structure to maximise the plasma wetted area for a given component length scale. This shape also allows tight packing of multiple modules on the divertor target plates. The internal surface of the hexagon was sub-divided into a number of cavities to accommodate high coolant pressures. This general design structure was termed the High Pressure Jet Cascade (HPJC).

A baseline design, called the HPJC-1a, has an hexagonal side length of approximately $10 \mathrm{~mm}$, and is sub-divided internally into six equilateral triangles, each with a side length of $6.8 \mathrm{~mm}$. These triangular cavities are cooled by a $0.8 \mathrm{~mm}$ diameter impinging jet ${ }^{1}$. This set of length scales was chosen to achieve an optimum Open Area Ratio $(\mathrm{OAR})]^{2}$ in the range of 1-3\% [20, 24], and ensure that pressure stresses in the impingement plate were below $\sim 0.5 \sigma_{y}$. A plan view and cross-section of this design are shown in Fig 1 .

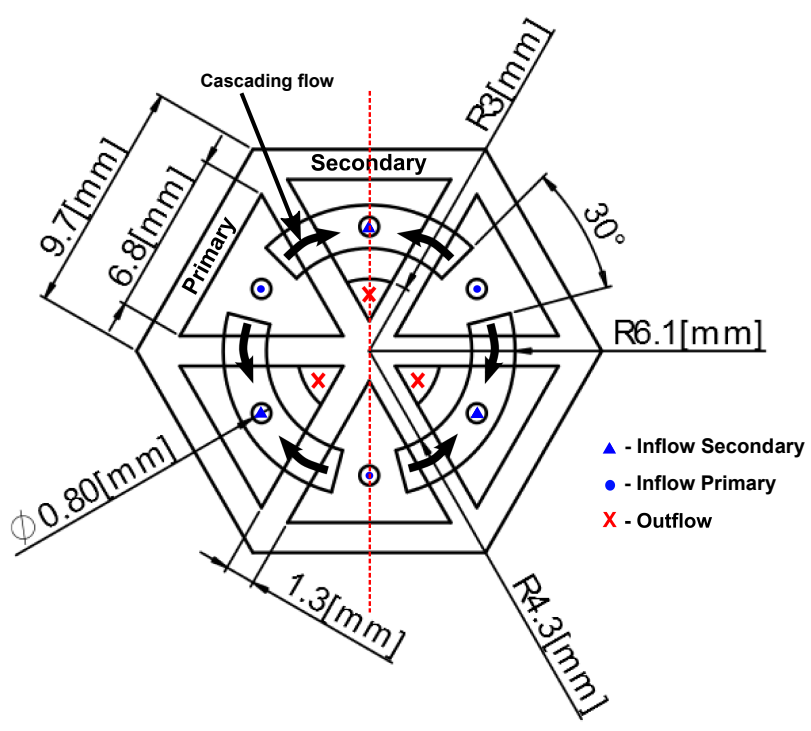

(a)

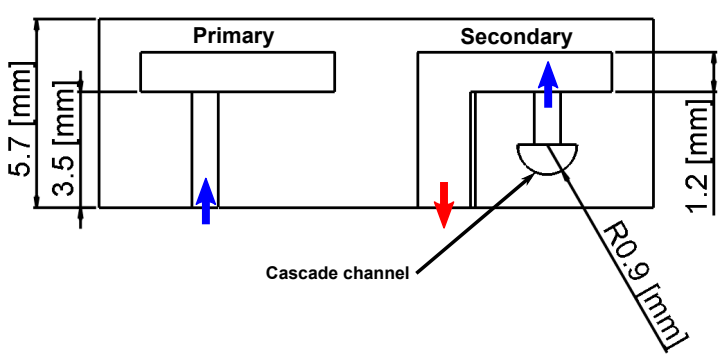

(b)

Figure 1: (a) Plan view of HPJC-1a cooling module geometry with flow path indication. (b) Cross-section through HPJC-1a along dashed red line in image (a). Semi-circular cascade channels are indicated along with coolant inflow (blue) and outflow (red) arrows.

To develop a quantitative understanding of the merits of the cascade concept, only a single cascade was used in the HPJC-1a. Jets were grouped, and then labelled, according to their position within the cascade. An ordinal numbering system was used, with the first set of jets in the cascade called the primary jets.

Three primary jets are first fed with coolant from a manifold. The spent flow from each of these jets then exists

\footnotetext{
${ }^{1}$ The minimum jet diameters employed in turbine blade cooling that avoid blockage are $\sim 0.5 \mathrm{~mm}[23$.

${ }^{2}$ The ratio of the area of the jet to the surface to be cooled
} 
through the two outlet ports, indicated in image (a) of Fig,1. This exhaust flow passes through a channel of semicircular cross-section, where it combines with exhaust flow from another primary jet. The re-combined flows then impinge through a secondary jet, before exiting via a central port.

The complete structure of the HPJC-1a is formed from three laminate $\mathrm{CuCrZr}$ sheets. Following jet impingement nomenclature these were called the impingement plate, jet plate and cascade plate. This structure is depicted in Fig, 2, with arrows representing fluid inflow (blue) and outflow (red) locations.

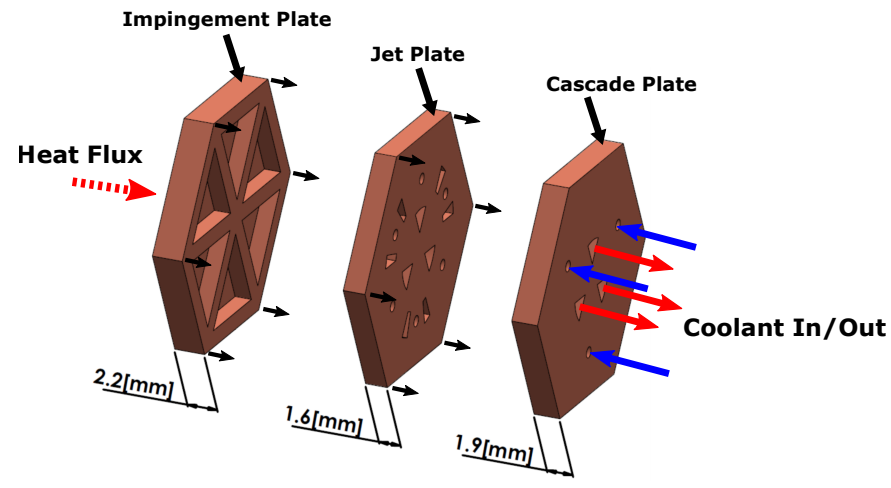

Figure 2: Constituent laminate $\mathrm{CuCrZr}$ sheets for HPJC-1a construction indicating fluid inflow (blue) and outflow (red) locations.

The jet exit plane was located $1.2 \mathrm{~mm}$ away from the impingement surface. In the literature, the ratio of this distance to the jet diameter $(\mathrm{Z} / \mathrm{D})$ has been shown to have a significant impact on the heat transfer performance [24, 25]. For a single jet the optimum value is found to be in the range of 4-6 [20], whilst for multiple jets it reduces to 1-3 24. A value of 1.5 is used for the HPJC-1a. This was a compromise between optimising heat transfer performance and minimising pressure stresses.

\section{Numerical Simulations}

\subsection{Methodology}

Steady-state conjugate CFD was performed on a $120^{\circ}$ periodic segment of the HPJC-1a using ANSYS CFX 15.0. It was assumed that the thermal resistance was dominated by the impingement plate and coolant heat transfer. This allowed the laminate structure to be modelled as a single solid body.

An unstructured mesh was created using ICEM in ANSYS 15.0. Approximately two million cells were used to model the fluid region, and one million in the solid. The mesh at the fluid-to-solid interface is shown in Fig 3 , along with a cross-section through the fluid domain. A number of prism layers were used to capture the gradients in the boundary layer at the fluid-to-solid interface. The thickness of the boundary layer was estimated to be $30 \mu \mathrm{m}$, based on a correlation for turbulent flow over a flat plate [26]. Prism layers were grown to this height using a growth ratio of 1.25 .

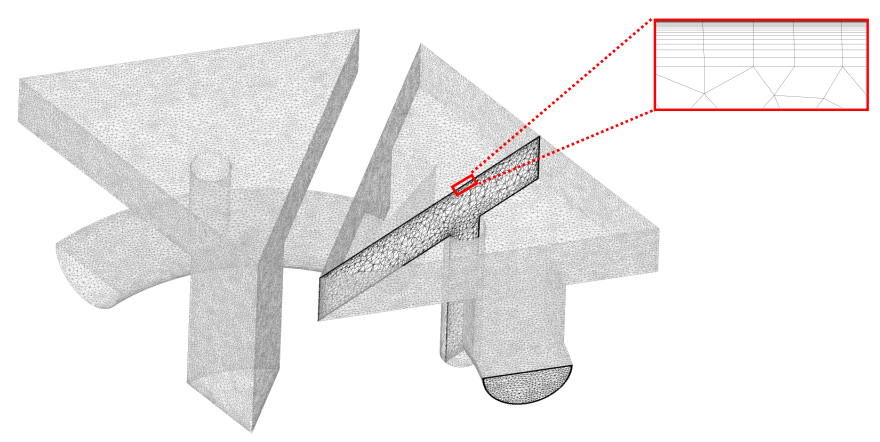

Figure 3: Fluid-to-solid boundary mesh for HPJC-1a geometry. Cross-section through fluid section shows boundary layer prisms.

Water was modelled using the in-built IAPWS-97 thermodynamic properties library, and assumed to be single phase. The reference pressure was set to 200 bar.

The minimum operating temperature of $\mathrm{CuCrZr}$ in a DEMO will be dictated by neutron embrittlement or corrosion. For the former, this results in a minimum temperature of $150-200^{\circ} \mathrm{C}$, depending on whether uniform elongation or fracture toughness is used as the criteria [4]. In this research the authors chose to use the upper bound. To meet this condition the coolant inlet temperature was set to $180^{\circ} \mathrm{C}$, which accounts for the fact that there will be a finite convective thermal resistance between the coolant and wall. The thermal properties of $\mathrm{CuCrZr}$ were taken from the ITER reference heat treatment in 27] and assumed constant; a reference temperature of $300^{\circ} \mathrm{C}$ was used.

A uniform heat flux was applied on the top of the impingement plate, and all other outer surfaces were assumed adiabatic. Interpolation of quantities between the mesh faces on the periodic boundaries was automated by ANSYS CFX 15.0 for both fluid and solid bodies. The area averaged static pressure was set to $0 \mathrm{~Pa}$ at the fluid outlet boundary, and a mass flow rate condition applied at the inlet. These boundary conditions are summarised in Fig 4

Convergence of the mass, momentum and energy residuals below $10^{-5}$ was achieved for all simulations. Additionally, energy imbalance for the solid and fluid domains was below $1 \%$.

\subsection{Turbulence Modeling}

The Reynolds numbers of the jets were of the order of $10^{4}$; in the turbulent flow regime. To capture the heat transfer at the impingement surface turbulence needs to be modelled accurately. We chose in this work to focus 


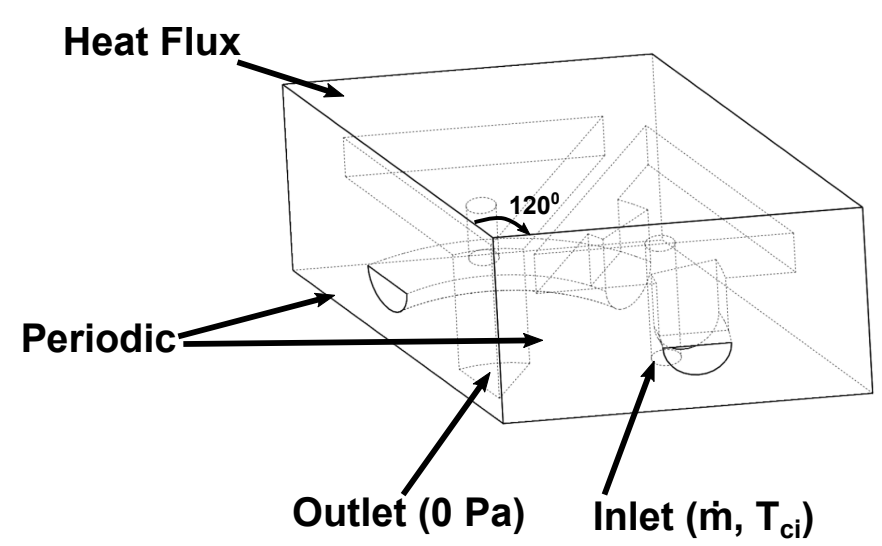

Figure 4: Thermo-fluid boundary conditions used for CFD on HPJCa-1a module.

on two-equation eddy viscosity turbulence models to close the RANS equations. These models have been used extensively in other fields to simulate jet impingement flows [20].

Of the two-equation turbulence models available in the ANSYS 15.0 CFX software, those based on the $k-\omega$ formulation were chosen for this study due to their ability to fully resolve the viscous sublayer. Though these low-Re models involve higher computational effort than employing a full wall function treatment, the accuracy of the results is generally considered superior as long as the boundary layer is sufficiently resolved [20].

A total of four models have been compared for the work: $k-\omega$, SST, Baseline (BSL) and the Baseline Explicit Algebraic Reynolds Stress Model (BSL-EARSM). This latter model is an extension of BSL to account for streamline curvature and secondary flow effects [28]. Both of these effects are important in jet impingement flow fields [29].

An automatic wall treatment was used for all of the models. This allows CFX to switch from a wall function, to a low-Re approach, where the boundary layer mesh is adequately refined [30. The accuracy of these models in predicting convective heat transfer and pressure drop results for the HPJCa-1a is compared with experimental data in Sec 5.3 .

\subsection{Mesh Sensitivity \& Independence}

To take advantage of the capability of $k-\Omega$ turbulence models to resolve the viscous sub-layer, $y^{+}$values of less than unity should be targeted at the fluid-to-solid interface [30.

A sensitivity study was performed on the HPJCa-1a mesh. The variation in peak $y^{+}$with jet Reynolds number, and near-wall mesh refinement, were both investigated. The impact of this latter effect was captured by varying the number of prisms layers from 14-20, whilst keeping the total height and growth ratio constant. At each level of refinement, simulations were run at a range range of Reynolds numbers. A fixed heat flux of $10 \mathrm{MW} / \mathrm{m}^{2}$ was applied to the impingement surface, and the turbulence modelled using SST. In Fig 5 the peak $y^{+}$is plotted against Reynolds number for varying levels of mesh refinement.

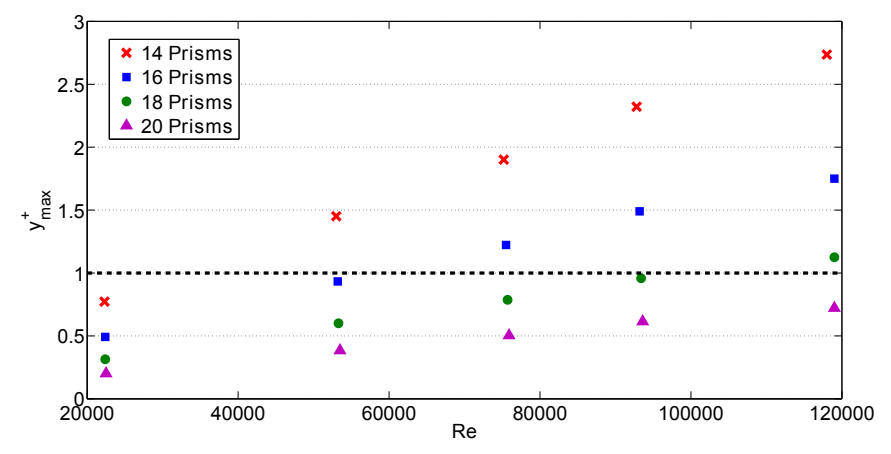

Figure 5: Maximum $y^{+}$on primary triangular surface for different levels of prism layer refinement.

At a fixed Reynolds number the peak $y^{+}$is seen to decrease with the number of prism layers. This is caused by the reduction in the first node spacing from the wall. If the number of prism layers is kept constant, and the Reynolds number increased, the value of $y^{+}$also increases. This is due to the fact that the wall shear stress is proportional to the Reynolds number.

It is evident that twenty prism layers are required to achieve a peak $y^{+}<1$ over the range of Reynolds numbers considered. The corresponding first node spacing from the solid wall was $\sim 0.12 \mu \mathrm{m}$.

Mesh independence at a local level was investigated by plotting the variation of the convective heat transfer along a line across the triangular cavity. This was done at a fixed Reynolds number for each level of mesh refinement. The heat transfer coefficient, $h_{c}$, was defined as

$$
h=\frac{q^{\prime \prime}}{\left(T_{w}-T_{j}\right)},
$$

where $q^{\prime \prime}$ represents the local wall heat flux, and $T_{w}$ the wall temperature at the equivalent location. The reference value $T_{j}$ is taken as the area averaged temperature of the fluid, one jet diameter upstream of the jet exit plane.

The Chilton j-factor [26], $j_{H}$, is a useful non-dimensional measure of convective heat transfer. It is defined as

$$
j_{H}=S t \cdot \operatorname{Pr}^{\frac{2}{3}}=\frac{N u}{R e \cdot \operatorname{Pr}^{\frac{1}{3}}} .
$$

It is an empirical relation valid for turbulent flows with $0.6<\operatorname{Pr}<60$ [26]. The form of this non-dimensional heat transfer parameter means that it is only weakly dependent on both the Reynolds and Prandtl numbers for a 
broad range of coolants and flow conditions. We choose to use this parameter as a measure of convective heat transfer to facilitate application of the HPJC-1a architecture to alternative coolant and heat sink material combinations.

Reference length scales and areas for $j_{H}$ were based on the jet diameter, and its cross-section, respectively. Fluid properties were taken at the film temperature, $T_{f}$, defined as

$$
T_{f}=\frac{T_{j e t}+T_{w_{\text {avrg }}}}{2}
$$

where $T_{w_{\text {avrg }} \text {. }}$ is the average temperature of the heat transfer surface of interest.

In Fig $6 j_{H}$ is plotted against the normalised distance along the primary cavity altitude ${ }^{3}$ for varying numbers of mesh refinement.

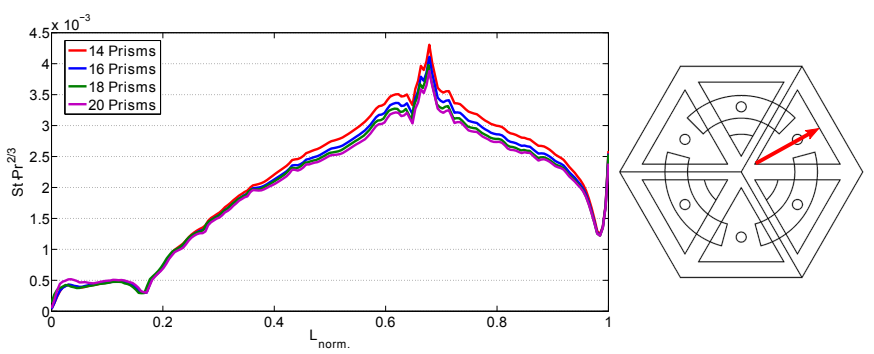

Figure 6: Variation in local j-factor along altitude path in primary cavity for different levels of boundary layer refinement.

As the number of prism layers is increased from 14-20, we see a reduction in the peak heat transfer predicted in the stagnation region of $\sim 10 \%$. The variation between different levels of refinement diminishes as the number of prism layers is increased. Between the 18 and 20 prism layer cases the peak value differs by only $\sim 2.5 \%$. This indicates that increasing the refinement further will have a negligible impact on the results. A final value of 20 prism layers was chosen for this research to ensure the predicted heat transfer was mesh insensitive for the range of Reynolds numbers of interest.

\section{Reference Case}

A reference simulation of the HPJC-1a was performed using the SST turbulence model at a heat flux of $10 \mathrm{MW} / \mathrm{m}^{2}$. The coolant mass flow rate was adjusted until the peak solid temperature was $350^{\circ} \mathrm{C}$. This is regarded as the maximum permitted operating temperature of $\mathrm{CuCrZr}$ to avoid severe thermal/irradiation creep and softening [31]. The

\footnotetext{
${ }^{3}$ The altitude of a triangle is a line segment through a vertex that meets the opposite side at 90 degrees.
}

purpose of this study was to determine whether the concept was capable of operating under DEMO level steadystate heat flux levels, and to compare it with an ITER-like DEMO design. A summary of the results is shown in Table 1.

\begin{tabular}{lccccc} 
Concept & $\begin{array}{c}\dot{\mathbf{m}} \\
\mathbf{A}\end{array}$ & $\begin{array}{c}\Delta \mathbf{P}_{\text {tot. }} \\
{\left[\mathrm{kg} / \mathrm{m}^{2} \mathrm{~s}\right]}\end{array}$ & $\begin{array}{c}\boldsymbol{\Delta} \mathbf{T}_{\text {fluid }} \\
{[\mathrm{kPa}]}\end{array}$ & $\begin{array}{c}\mathbf{P}_{\mathbf{w}} \\
{\left[\mathrm{kW} / \mathrm{m}^{2}\right]}\end{array}$ & $\begin{array}{c}\mathbf{v} \\
{[\mathrm{m} / \mathrm{s}]}\end{array}$ \\
\hline \hline HPJC-1a & 56 & 140 & 41 & 8.6 & 10 \\
ITER-like & 5300 & 8.0 & 0.4 & 49 & 20 \\
\hline \hline
\end{tabular}

Table 1: Comparison of the HPJC-1a and ITER-like DEMO divertor 16. 32 concepts for a $10 \mathrm{MW} / \mathrm{m}^{2}$ heat flux. The HPJC-1a results come from conjugate CFD simulations at a fixed peak solid temperature of $350^{\circ} \mathrm{C} . P_{w}$ is the pumping power per square metre, and $v$ the characteristic flow velocity.

The ITER-like values in Table 1 were based on the results of [16]. It was deemed a fair comparison by the authors as both the incident heat flux, and difference between the coolant inlet temperature and peak heat sink temperature, was equivalent for both concepts. To calculate the pressure drop the swirl tape was assumed to have a twist ratio of two, and be $0.8 \mathrm{~mm}$ thick 32 .

It is evident from able 1 that the HPJC-1a operates at considerably lower mass flow rates than the ITER-like DEMO design. This results in increased coolant outlet temperatures. This benefit could be offset if the pumping powers are excessive. However, it is found that the HPJC-1a pumping powers are over five-fold smaller than those for an ITER-like DEMO. Proponents of the ITER-like design may argue that the swirl tape will only be employed in the region around the strike point, so that the actual pumping powers will be considerably lower. This neglects the modular nature of the HPJC-1a, which would allow an even finer degree of control over optimising the mass flow distribution to minimise the total pumping power.

In the following sections local results from this simulation are considered in detail.

\subsection{Impingement Surface Convective Heat Transfer}

A contour plot of $j_{H}$ over the impingement surfaces is shown in Fig.7.

For each jet the convective heat transfer is a maximum in the stagnation region, and deteriorates moving outwards along the impingement surface. The maximum $j_{H}$ values are $\sim 3.8 \%$ larger for the secondary jets. When the $j_{H}$ values are averaged over the impingement surfaces there is negligible differences found between the cavities. As the only geometric variation between the primary and secondary jet cavities is the outlet locations and jet entry length, these results imply that the influence of these factors on the jet flow field is minimal. 


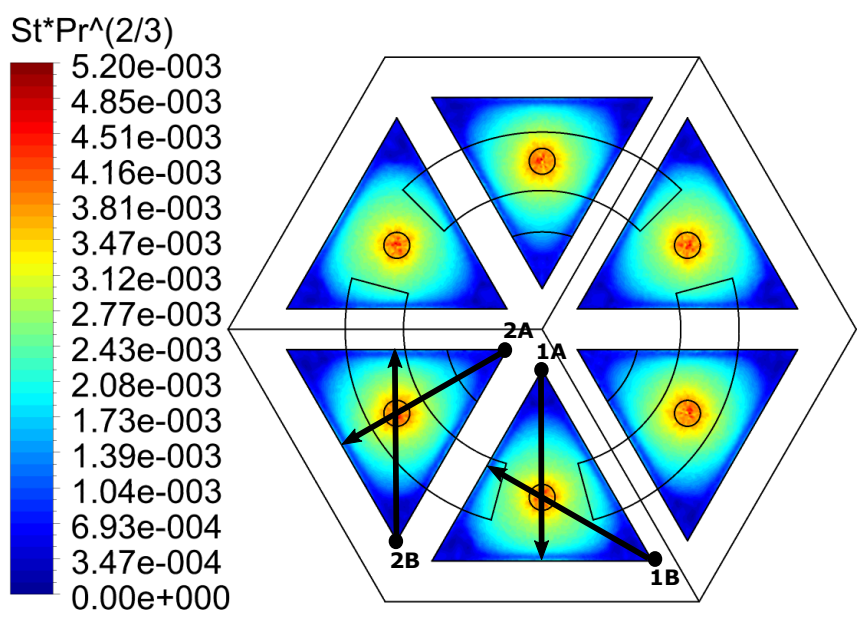

Figure 7: Contour plot of $j_{H}$ over the triangular impingement surfaces for the reference case. Local data are also shown emanating from vertices $1 \mathrm{~A}, 1 \mathrm{~B}, 2 \mathrm{~A}$ and $2 \mathrm{~B}$.

Convective heat transfer near the triangular vertices on the impingement surface is negligible in comparison to the stagnation region. This non-uniformity in the distribution leads to corresponding non-uniformities in the solid temperature field, which generate thermal stresses.

To illustrate the variation in the local convective heat transfer over the cavity surfaces, line data were taken along altitudes originating at vertices $1 \mathrm{~A}, 1 \mathrm{~B}, 2 \mathrm{~A}$ and $2 \mathrm{~B}$ - see Fig.7. These results are shown in Fig.8.

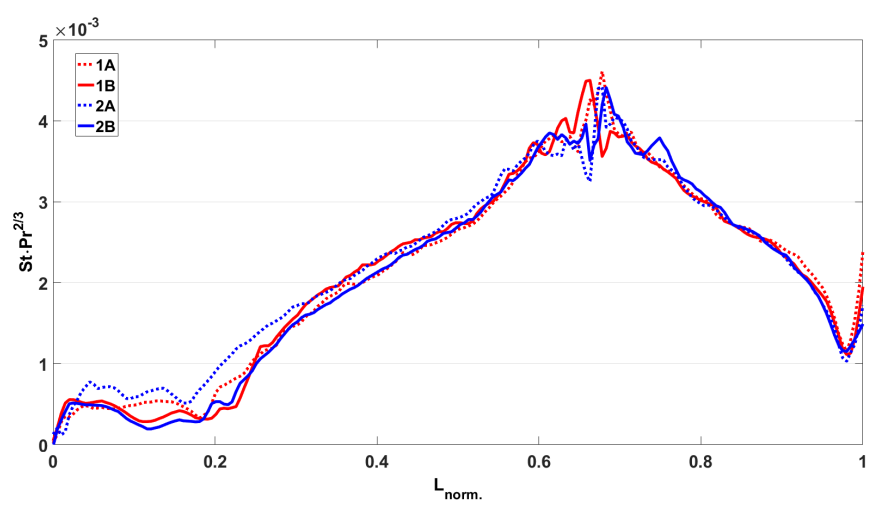

Figure 8: Local variation of $j_{H}$ along altitudes in both primary and secondary cavities. These altitudes are depicted in Fig 7

Fig.8 corroborates the previous statement that the convective heat transfer is largely independent of the chosen cavity. The figure also shows that, away from the side walls, the heat transfer is approximately symmetric about the cavity orthocentre 4 . This implies that there is minimal cross-flow being generated.

\footnotetext{
${ }^{4}$ The point where all three altitude lines of a triangle intersect.
}

\subsection{Solid Temperature Distribution}

Approximately $51 \%$ of the impingement plate surface area in the HPJC-1a is covered with the webs that form the internal cavities. This facilitates conduction heat transfer to the cascade plate. If the heat transfer coefficients in the cascade plate are also low, then the minimum solid temperature may be maintained significantly above the coolant inlet temperature. This would mean the coolant inlet temperature could be reduced, and the minimum temperature of the $\mathrm{CuCrZr}$ still maintained above the embrittlement limit. At the same coolant flow rate, this would increase the heat flux handling capacity, but at the expense of a larger temperature gradient through the structure.

The lowest solid temperatures in the HPJC-1a occur near the primary jet inlet ports, at the fluid interface. A contour plot of this surface is shown in image (a) of Fig 9 .

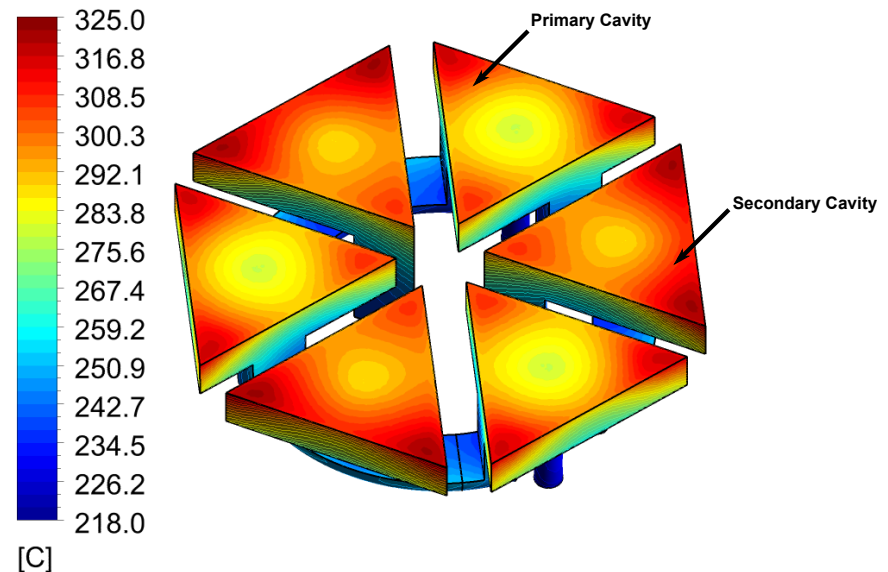

(a)
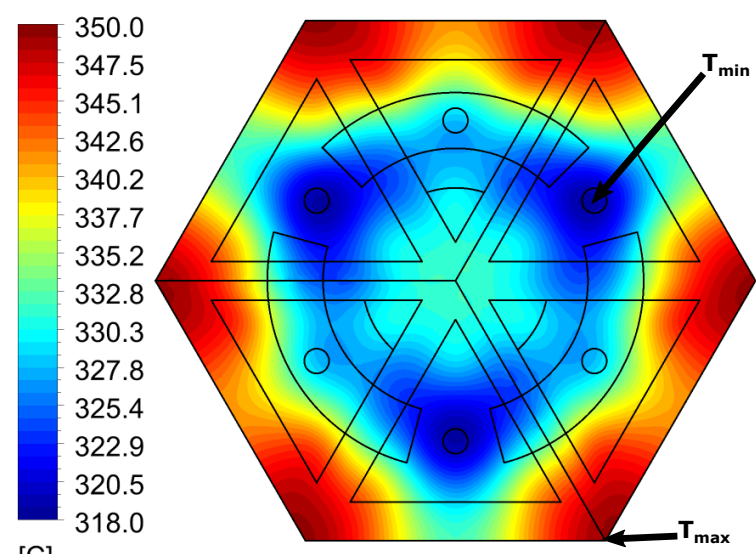

(b)

Figure 9: Contour plots of temperature distributions in the HPJC-1a at (a) the fluid-to-solid interface; (b) the heat flux surface.

The minimum temperature of the $\mathrm{CuCrZr}$ is $218^{\circ} \mathrm{C}$, which is $38^{\circ} \mathrm{C}$ above the coolant inlet temperature. This vali- 
dates the hypothesis, and provides a simple means of improving the heat flux handling capacity of the HPJC-1a.

In image (b) of Fig 9 the temperature distribution on the heat flux surface is shown. The global peak solid temperatures occur on this surface at the hexagonal vertices. There are two mechanisms that drive the higher temperatures at these points: (1) the increased conduction path length relative to the plate thickness; (2) the low convective heat transfer in these regions. Point (1) could be addressed by reducing the thickness of the outer walls of the hexagon. However, doing this would increase the pressure stresses and reduce the bonding area. Adapting the shape of the cavity or the location of the jets would address (2).

\section{Experimental Comparison}

\subsection{Methodology}

An experimental campaign was undertaken to validate the numerical approach. Reynolds numbers were matched with air as the working fluid. This required the HPJCa-1a design to be scaled to ten times the divertor target plate application size. Perspex was used as the construction material to allow easy visual access to the rig, and because of its well documented thermal properties.

A regulated 100 psi air line was used to feed the three primary jets. Orifice meters were installed within each of the three inlet channels to measure the flow rates. These had all previously been calibrated against a BS 1042 orifice meter. A single channel was used for the combined outlet port exhaust. This was restricted with an orifice to provide back-pressure to stabilise the flow. In Fig 10 a flow schematic for the rig is shown.

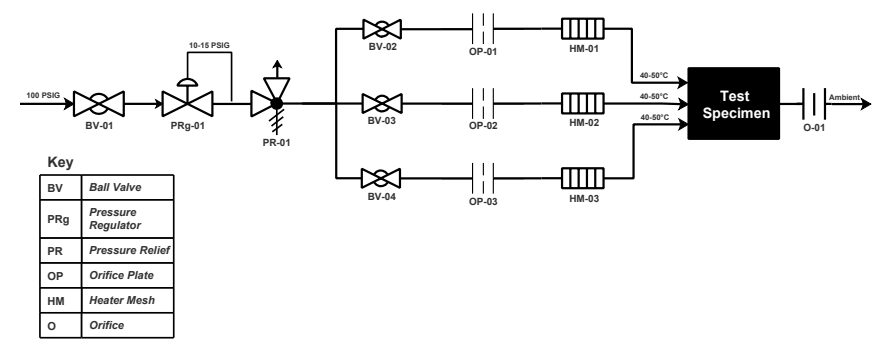

Figure 10: Flow diagram for the experimental rig used to validate the CFD results.

The transient heat transfer method, together with a coating of thermochromic liquid crystals, were used to measure the heat transfer coefficients over the impingement surface 33 35. These crystals respond to a change in temperature by altering their optical properties. For the narrow band variety used, this occurs over a small temperature interval $0.5^{\circ} \mathrm{C}$, allowing an accurate map of temperature to reflected light to be achieved; often involving the green signal. Crystals with differing colour play temperatures can be mixed and sprayed onto the surface from which heat transfer coefficient measurements are to be made. The crystals are encapsulated in polymer micro-capsules by the manufacturer and then sprayed onto a black background to enhance visible contrast. For this research, crystals with quoted band temperatures centred around 25 and $30^{\circ} \mathrm{C}$ were used.

The response of the perspex surface to heating is modelled using the solution to the transient one-dimensional Fourier equation for a semi-infinite solid under conditions of a step change in the driving gas temperature. Electrically heated meshes are placed in each inlet channel to achieve this temperature step change. The DC power to these meshes was supplied using a $600 \mathrm{~W}$ inverter powered from the mains. For complete information about the data processing for this established experimental method see 36.

\subsubsection{Data Capture}

Gas temperature thermocouples are placed in the jet orifice to record the variation in driving gas temperature throughout the experiment. Additional gas thermocouples were also placed at other locations in the assembly, and thin-foil thermocouples fixed to the cavity impingement surfaces. These latter thermocouples were used to obtain a temperature against green intensity calibration curve for the thermochromic liquid crystals. The importance of performing this calibration is evident from Fig.11. If the colour play temperature quoted by the manufacture had been used there would have been a discrepancy at the lower temperature of $\sim 1.5^{\circ} \mathrm{C}$. Both thermocouples and mesh voltage readings were recorded using a data logger at a frequency of $40 \mathrm{H}^{5}$

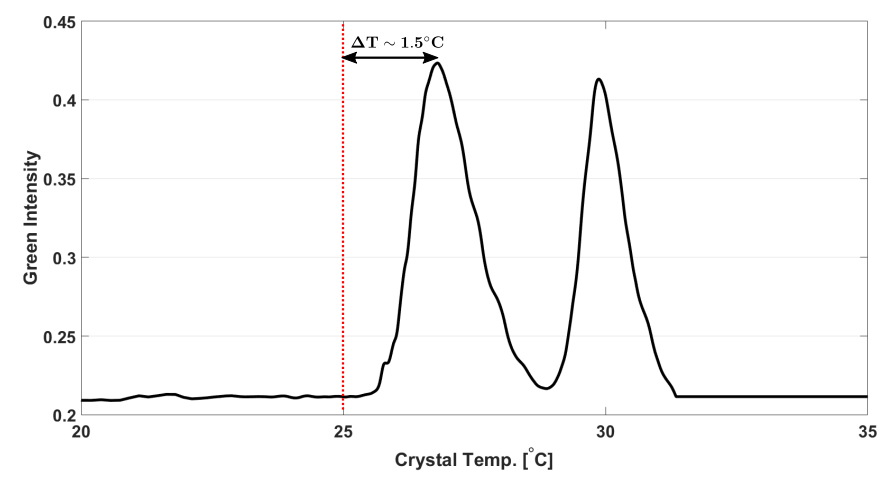

Figure 11: Calibration curve for the thermochromic liquid crystals sprayed onto the heat transfer surface. Green intensity is plotted against the temperature recorded by the surface thermocouple.

Video data for the liquid crystals was recorded using a

${ }^{5}$ OM-DAQ-USB-2400 
CMOS camera ${ }^{6}$ at a rate of 32 frames per second. An LED was placed in the capture frame that was activated once power was supplied to the heater meshes. This allowed time synchronisation of the video and thermocouple data for subsequent analysis. The experiment was limited to a maximum run-time of $50 \mathrm{sec}$ to ensure the validity of the transient assumption 37. A CAD drawing of the test section, along with a typical image of the impingement surface during a run, is shown in Fig.12.

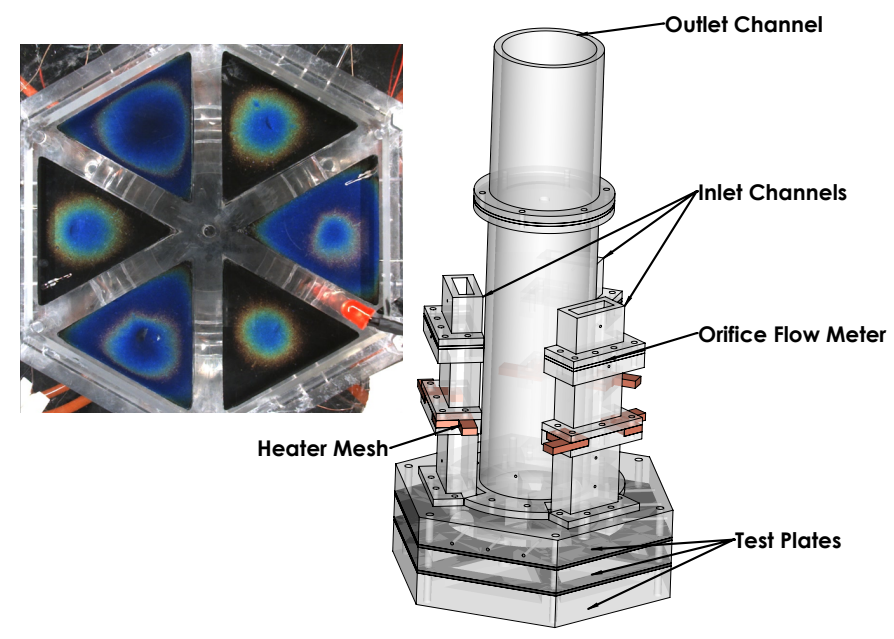

Figure 12: Typical images of the liquid crystal coating during an experiment [left]. Experimental test section set-up [right] for thermochromic liquid crystal heat transfer measurements.

Separate steady-state tests were run to gather pressure drop data. Static pressure tappings were placed throughout the assembly and readings taken using a digital manometer.

\subsection{Uncertainty Analysis}

To estimate the uncertainty in the heat transfer coefficient data the small perturbations method of 38 was used. The partial derivatives for each variable were found numerically using the central differencing method. This is expressed mathematically for a variable, $\chi_{i}$, as [39]

$$
\frac{\partial h_{c}}{\partial \chi_{i}}=\frac{h_{c}\left(\chi_{i}+\delta \chi_{i}\right)-h_{c}\left(\chi_{i}-\delta \chi_{i}\right)}{2 \delta \chi_{i}}
$$

where $\delta \chi_{i}$ is a small perturbation in the chosen variable. The expected percentage uncertainty in the heat transfer coefficient, $\epsilon_{i}$, for each $\chi_{i}$ can be estimated from

$$
\epsilon_{i}=\left(\frac{\partial h_{c}}{\partial \chi_{i}}\right) \frac{\Delta \chi_{i}}{h_{c}} .
$$

Here $\Delta \chi$ is the uncertainty in the variable measurement,

\footnotetext{
${ }^{6}$ Point Grey Blackfly PGE-13E4C-CS
}

and the value used for $h_{c}$ should be taken as the most likely result. An estimate of the overall uncertainty was then made using the root sum square method, such that

$$
\epsilon_{t o t}=\sqrt{\sum_{i=1}^{n}\left[\left(\frac{\partial h_{c}}{\partial \chi_{i}}\right) \frac{\Delta \chi_{i}}{h_{c}}\right]^{2}}
$$

The results of these analyses for the area averaged heat

\begin{tabular}{|c|c|c|c|c|}
\hline Parameter & Typical Value & Measurement Uncertainty & $\frac{\partial h_{c}}{\partial \chi}$ & $\frac{\partial h_{c}}{\partial \chi} \frac{\Delta \chi}{h_{c}}$ \\
\hline \multicolumn{5}{|c|}{ Primary Cavity } \\
\hline$T_{c}$ & $35^{\circ} \mathrm{C}$ & $0.30^{\circ} \mathrm{C}$ & 45 & 0.060 \\
\hline$T_{j}$ & $40^{\circ} \mathrm{C}$ & $0.20^{\circ} \mathrm{C}$ & -51 & -0.046 \\
\hline$\sqrt{\rho c k}$ & $570 \mathrm{Jm}^{-2} \mathrm{~K}^{-1} \mathrm{~s}^{-0.5}$ & $29 \mathrm{Jm}^{-2} \mathrm{~K}^{-1} \mathrm{~s}^{-0.5}$ & 0.34 & 0.047 \\
\hline$t$ & $50 \mathrm{~s}$ & $0.030 \mathrm{~s}$ & 44 & 0.0060 \\
\hline RSS Error & & & & 0.089 \\
\hline \multicolumn{5}{|c|}{ Secondary Cavity } \\
\hline$T_{c}$ & $30^{\circ} \mathrm{C}$ & $0.30^{\circ} \mathrm{C}$ & 62 & 0.082 \\
\hline$T_{j}$ & $35^{\circ} \mathrm{C}$ & $0.20^{\circ} \mathrm{C}$ & -86 & -0.075 \\
\hline$\sqrt{\rho c k}$ & $570 \mathrm{Jm}^{-2} \mathrm{~K}^{-1} \mathrm{~s}^{-0.5}$ & $29 \mathrm{Jm}^{-2} \mathrm{~K}^{-1} \mathrm{~s}^{-0.5}$ & 0.54 & 0.069 \\
\hline$t$ & $50 \mathrm{~s}$ & $0.030 \mathrm{~s}$ & -25 & -0.0034 \\
\hline RSS Error & & & & 0.13 \\
\hline
\end{tabular}
transfer coefficients in the primary and secondary jet cavities are shown in Table.2.

Table 2: Uncertainty analysis for the area averaged heat transfer coefficients in the cavities for the primary and secondary jets. Area averaged reference heat transfer coefficient $\sim 225 \mathrm{~W} / \mathrm{m}^{2} \mathrm{~K}$.

The largest uncertainty for both cavity jets is in the temperature measured by the liquid crystal coating. This uncertainty is approximately $38 \%$ higher for the cavities fed by the secondary jets, which is caused by the reduced jet driving temperature - the heat transfer coefficient is dependent on the temperature difference between the wall and jet. As this difference decreases, uncertainties in either can cause a large percentage change in the calculated heat transfer coefficient.

\subsection{Results}

5.3.1. Area Averaged and Stagnation Point Heat Transfer

Experimental heat transfer coefficient data were processed using a MATLAB 2016a code developed by [37]. As flow rates through the secondary jets could not be measured individually, an even split of the total mass flow was assumed. This was considered reasonable, as the model was carefully assembled and its components machined to tight tolerances; $\sim 0.1 \mathrm{~mm}$ for features.

The thermo-physical properties of air were based on the driving gas temperature, rather than the film temperature. As the step change from the heater mesh was limited to $\sim 40^{\circ} \mathrm{C}$, this introduced negligible uncertainty. The Prandtl number was fixed at a value of 0.71 .

Comparative CFD simulations were run for each of the turbulence models discussed in Sec 3.2. The heat flux was reduced to $2 \mathrm{MW} / \mathrm{m}^{2}$ to ensure single-phase flow for the 
range of inlet mass flow rates considered. All other data were processed using the methodology set out in Sec.4.

The area averaged $j_{H}$ were calculated from the experimental results for both the primary and secondary jet cavities. These results are compared against the CFD in Fig 13 for varying Reynolds numbers.

Focussing initially on the variation between turbulence models; there is a trend of increasing spread in the results with Reynolds number for both jet cavities. This is caused by two mechanisms: (a) the jet turbulence intensity; (b) the entry length. For all turbulence models the primary jets had their turbulence intensity set to $5 \%$ at the inlet boundary. Area averaged values of this quantity for the SST model, over a plane one jet diameter upstream of the exit plane, decreased by only $22 \%$ as the Reynolds number increased from $\sim 10,000-40,000$. In contrast, for the secondary jets, the area averaged turbulence intensity over an equivalent plane increased almost three-fold for the same Reynolds number range. This indicates that the spread in the primary jet results is driven by (b). In contrast, for the secondary jets, the strong dependence of the turbulence intensity on the specific turbulence model leads to the increased spread observed. Experimentally it has been found that a higher turbulence intensity reduces the jet core length, which reduces the optimum Z/D [20].

For a particular turbulence model there is minimal difference between the area averaged convective heat transfer in the primary and secondary jet cavities. The lowest absolute values are obtained using the SST model, and the highest with BSL-EARSM. The dependence of the convective heat transfer on the Reynolds number is predicted to be slightly reduced for the secondary jet cavity.

All of the turbulence models are able to correctly predict the area averaged heat transfer for the primary jet cavity to within experimental uncertainty. The experimental results show an increased dependence on the Reynolds number in comparison to the CFD.

Only the SST model is able to correctly predict the area averaged convective heat transfer in the secondary jet cavity to within experimental uncertainty. There is also seen to be a more significant drop in Reynolds number dependence than predicted by the CFD.

The two correlations plotted in Fig, 13 are for a single jet in both confined 40], and un-confined [41, configurations. Data from the literature shows that confining a jet reduces its heat transfer performance [42, which is corroborated here. The correlation by Shoukri and Calka is found to be accurate to within $\sim 20-25 \%$ for both sets of cavity results.

A comparison between the CFD and experimental results for the stagnation point convective heat transfer in the pri- mary and secondary jet cavities is shown in Fig, 14. In both cases it is evident that the numerical results over-predict the experimental values. This trend has been observed in other experimental research on jet impingement heat transfer [4].

All of the turbulence models over-predict the peak convective heat transfer in the primary jet cavity by $50-60 \%$. For the secondary jet cavity the difference reduces to $25-50 \%$. The percentage discrepancy decreases for the primary jet cavity, but increases for the secondary jet cavity, at higher Reynolds numbers. The SST turbulence model again offers the best match to the experimental results.

The CFD successfully predicts that the stagnation point heat transfer will be higher in the secondary jet cavities. However, it underestimates the percentage difference by $10-20 \%$.

A correlation by [44] was also plotted in Fig, 14 for two different jet entry length ratios. It is able to predict the stagnation point heat transfer for both jet cavities to within $\sim 20 \%$. Additionally, it captures the behaviour of increasing stagnation point heat transfer with reducing jet entry length found in the experimental results.

\subsubsection{Local Convective Heat Transfer}

To investigate the differences between the experimental and CFD results further, local data were plotted along altitude lines for each jet cavity at a Reynolds number of $\sim 40,000$. Two altitude lines were considered for each jet cavity starting at vertices $1 \mathrm{~A}, 2 \mathrm{~A}, 1 \mathrm{~B}$ and $2 \mathrm{~B}$ - see Fig 7 from Sec 4 . Fig 15 shows the results for altitude lines running from vertices $1 \mathrm{~A}$ and $2 \mathrm{~A}$.

Considering the primary jet cavity results first: the experimental distribution agrees closely with the CFD in the stagnation region for all of the turbulence models. However, at the stagnation point, the CFD over-predicts the heat transfer, which leads to the observed spikes in the profiles. This is a result of the difficulty of accurately resolving the large velocity gradients at this point.

In the secondary jet cavity stagnation region there is a more significant discrepancy between the experimental and CFD profiles. The experimental distribution is broader than in the primary jet cavity, and the CFD only partially captures this. Such broadening of the stagnation region has been observed by [20] and is due to the reduced jet entry length.

In both experimental profiles there is a noticeable transition from a laminar to turbulent boundary layer in the wall jet region at a normalised distance of approximately 0.5. For normalised lengths below 0.5 the CFD under-predicts the recorded heat transfer for all turbulence models. This change in profile, caused by boundary layer transition was 


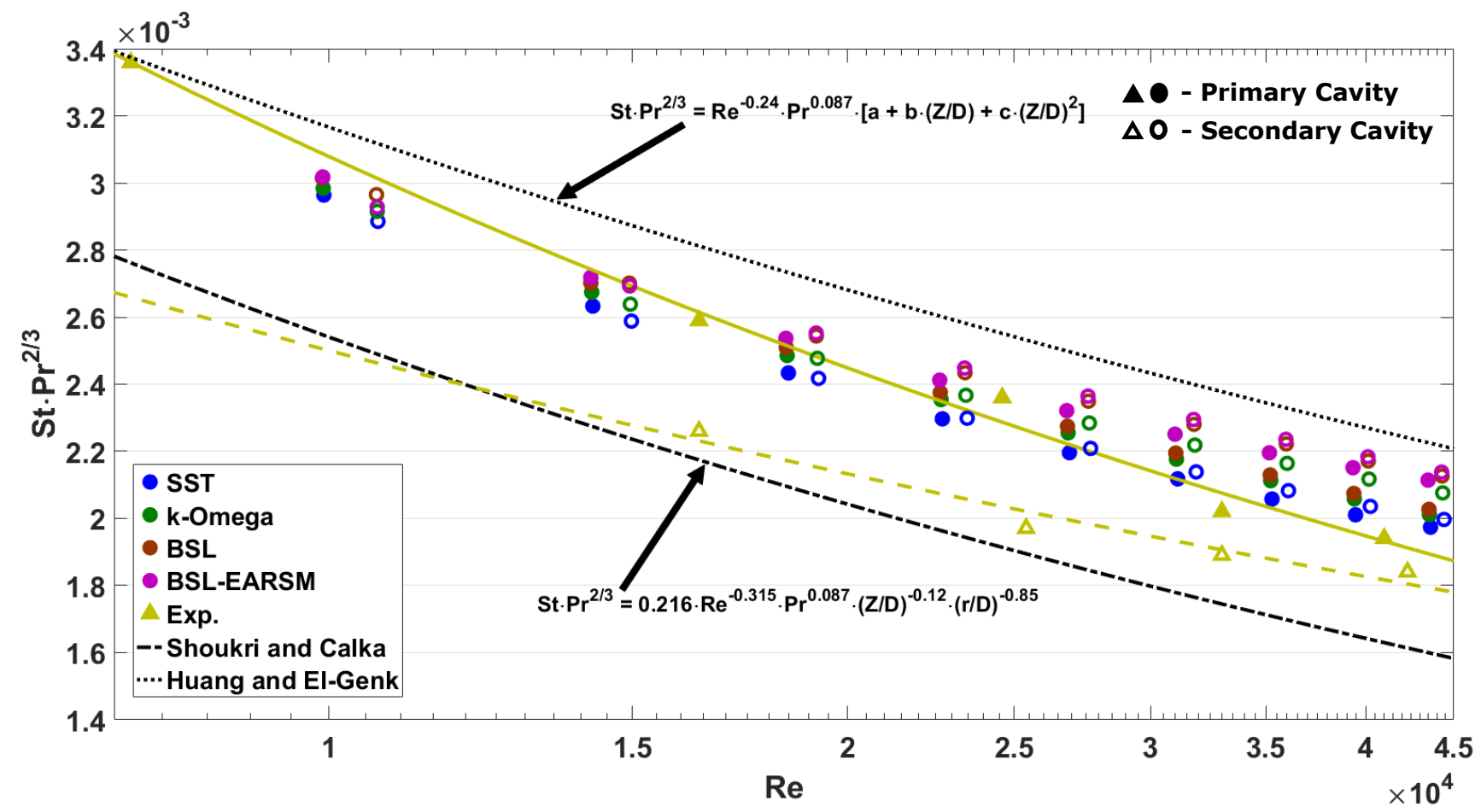

Figure 13: Variation of area averaged $j_{H}$ with Reynolds number. Primary jet cavity CFD and experimental data shown with solid markers, hollow markers used for secondary jet cavity data. Correlations from the literature have also been plotted [40, 41].

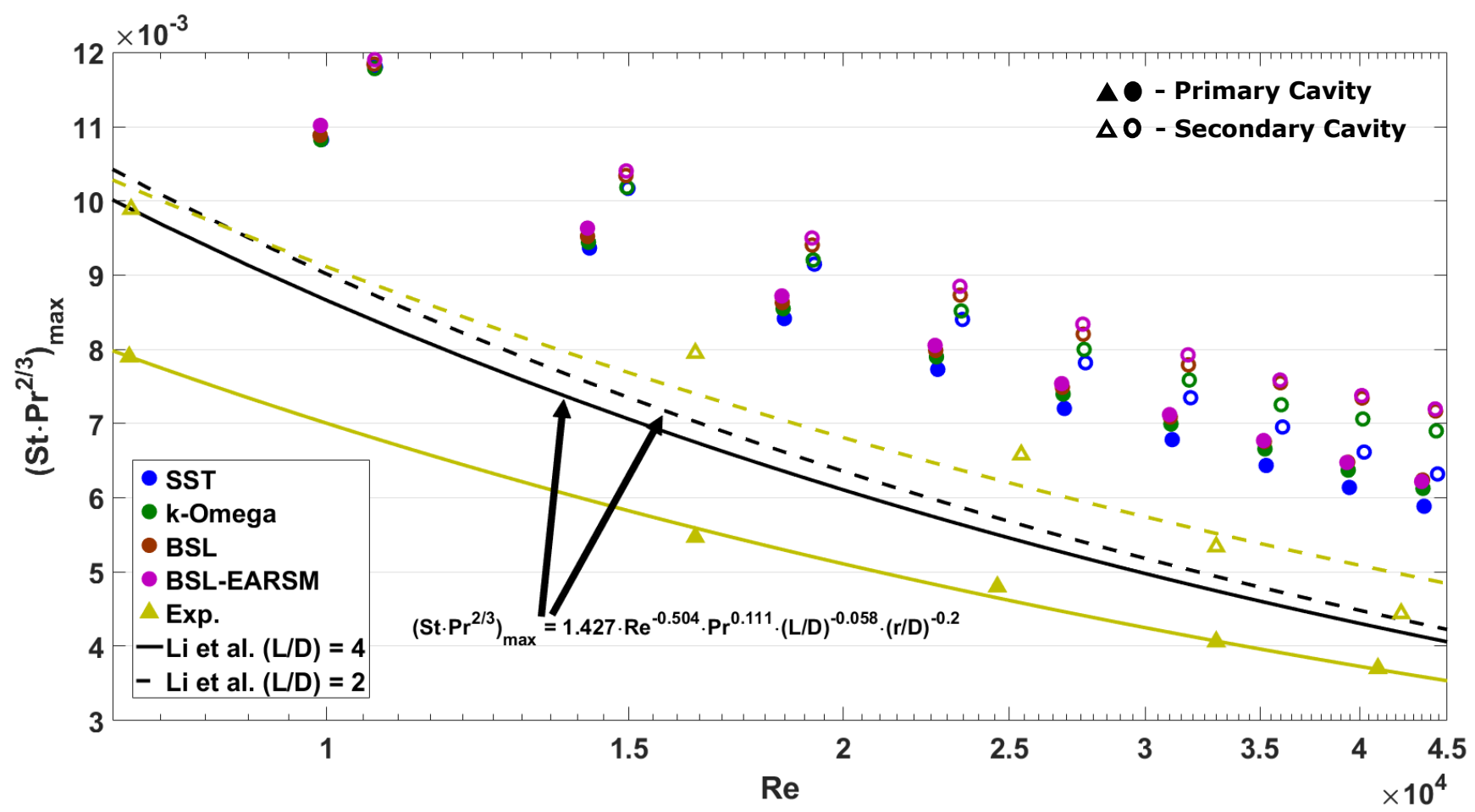

Figure 14: Variation of the stagnation point $j_{H}$ with Reynolds number. Primary jet cavity CFD and experimental data shown with solid markers, hollow markers used for secondary cavity data. A correlation from the literature has also been plotted for different jet entry lengths $[?]$.

studied in detail by [45.

Above a normalised distance of $\sim 0.95$ there is a drop in the heat transfer predicted by the CFD for both jet cavities, 

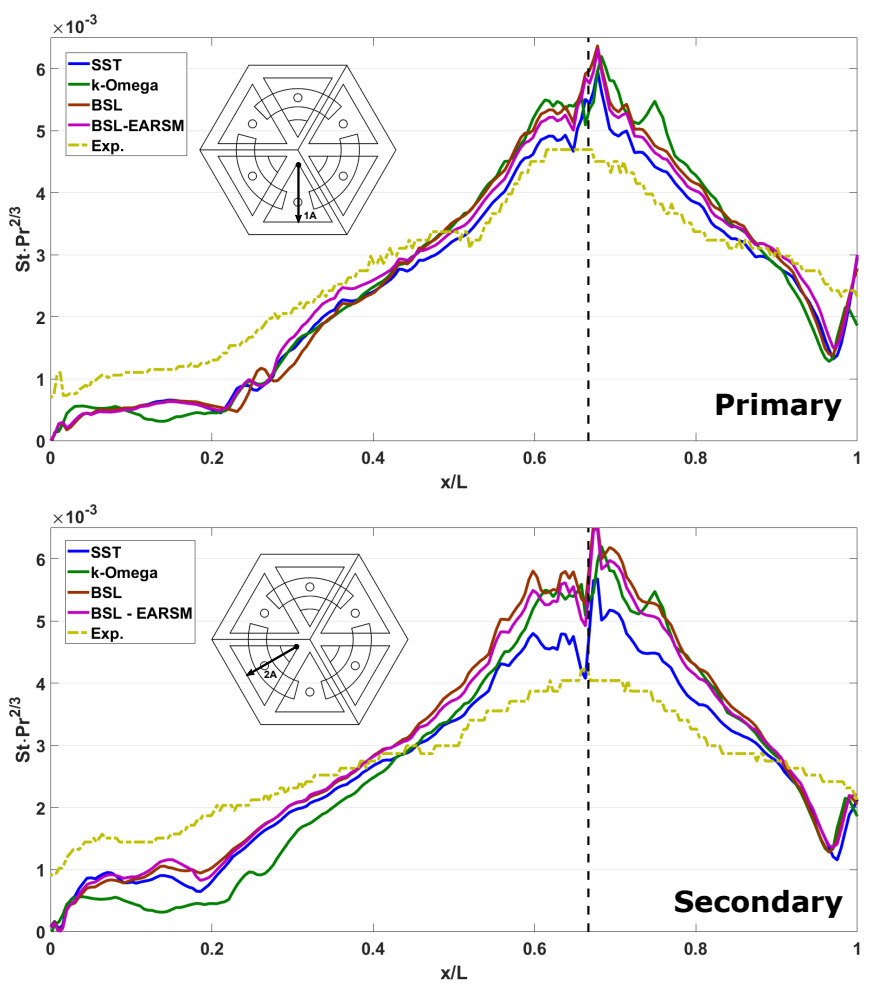

Figure 15: Local distribution of $j_{H}$ for both the primary and secondary jet cavities along altitudes originating from vertices $1 \mathrm{~A}$ and $2 \mathrm{~A}$. Data is shown for a range of turbulence models against the experimental results. A dotted line is shown to represent the jet centreline.

followed by a recovery. This is due to flow separation, and subsequent re-attachment, caused by the un-filleted corner at the edge of the cavity. In the experimental results this is not observed because the fabricated perspex components had filleted edges. The influence of impingement surface fillet radii on convective heat transfer has been investigated thoroughly by 46 .

The close agreement between the CFD and experimental area averaged heat transfer values for both jet cavities indicates that over predictions and under predictions must approximately cancel out. Local heat transfer profiles are most accurately re-produced by the SST turbulence model.

Results for the local profiles along altitudes originating from vertices $1 \mathrm{~B}$ and $2 \mathrm{~B}$ are shown in Fig 16 .

In comparison with the previous results for the primary jet cavity, there is a more significant under-prediction of the heat transfer in the wall jet region. The situation is reversed for the secondary jet cavity where the BSL-EARSM turbulence model matches the experimental profile well for $x / L<0.4$.

Fig 17 shows contour plots of $j_{H}$ at a fixed Reynolds number of $\sim 40,000$ for the CFD and experimental results.
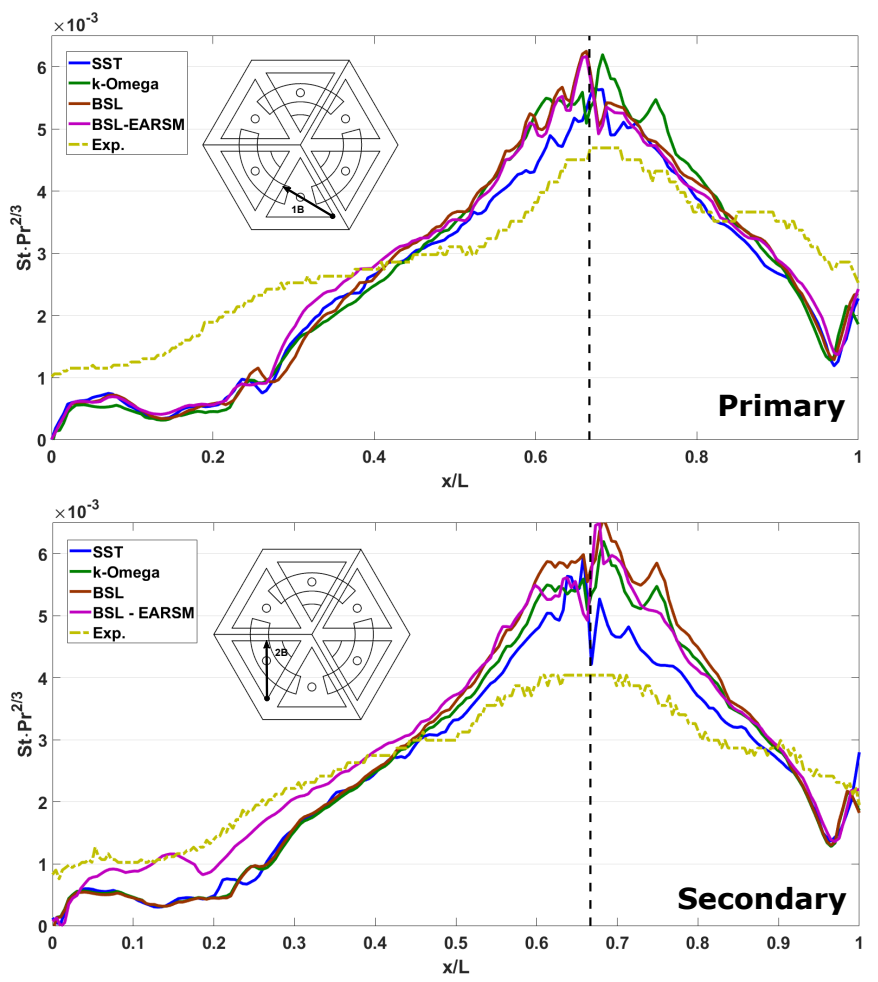

Figure 16: Local distribution of $j_{H}$ for both the primary and secondary jet cavities along altitudes originating from vertices $1 \mathrm{~B}$ and 2B. Data is shown for a range of turbulence models against experimental results. A dotted line is shown to represent the jet centreline.

The experimental heat transfer profiles are flatter than those predicted by the CFD. This is beneficial from a thermal stress perspective as it will result in reduced solid temperature non-uniformity.

\subsubsection{Pressure Drop}

In this section the pressure drop performance of the HPJC-1a is considered. The Euler number, $E u$, is plotted against the Reynolds for the experimental and CFD results in Fig, 18. Thermo-physical properties were taken at the average bulk temperature of the fluid, and the crosssectional area of the jet used as the reference area.

The average discrepancy between experiment and CFD is $\sim 13 \%$. This is above the measurement uncertainty of $0.1 \%$. From the CFD, approximately $91 \%$ of the total pressure drop through the system occurs across the jets, and in the impingement cavity regions. A study by 47 considered the influence of manufacturing tolerances on the total pressure drop of a jet impingement system. They found that an uncertainty in the jet diameter of $\pm 2.5 \%$ resulted in a corresponding change in the total pressure drop of $\pm 35 \%$. The uncertainty in the jet diameter from the machining methods used in this research is $\pm 1 \%$. It is therefore conceivable that the discrepancy between the numerical and experimental pressure drop measurements is caused by this uncertainty. 

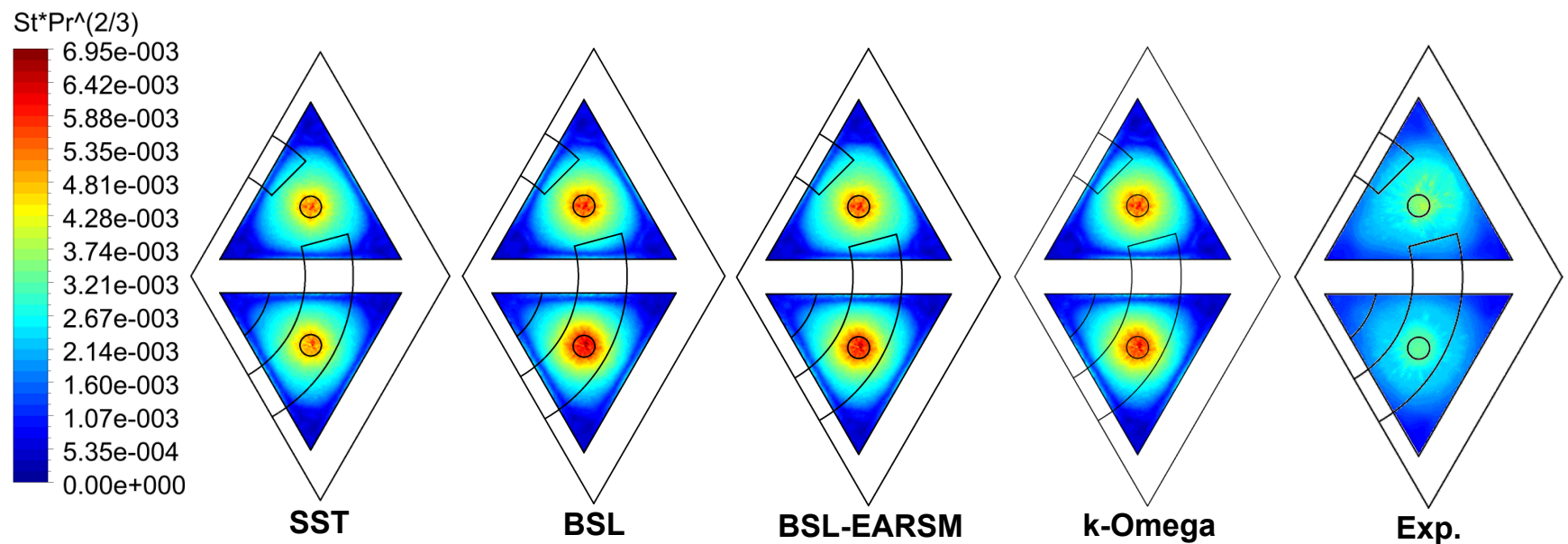

Figure 17: Comparative contour plots of $j_{H}$ for CFD and experimental results. Data is for a fixed fixed Reynolds number of 40,000. Turbulence models: $k-\Omega$, SST, BSL and BSL-EARSM.

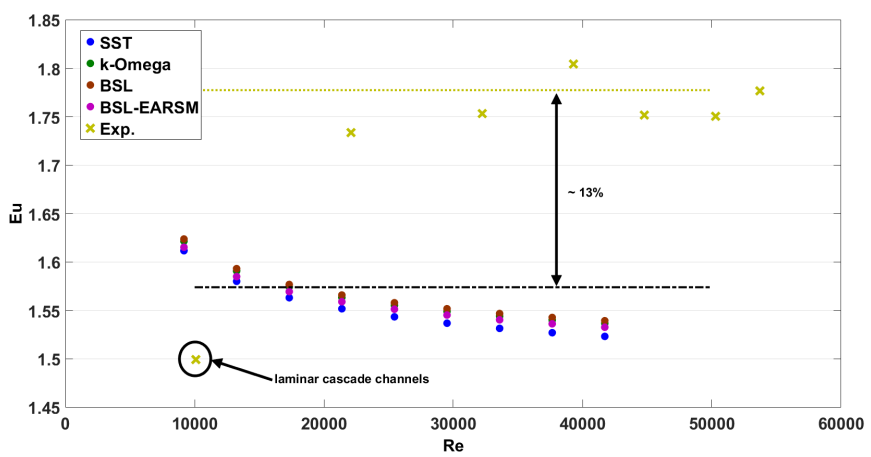

Figure 18: Variation of Euler number with Reynolds number for experimental and CFD results. Turbulence models: $k-\Omega$, SST, BSL and BSL-EARSM.

There is little variation in the results from the different turbulence models. All predict a slight reduction in Euler number with increasing Reynolds number. This is in contrast to the experimental results, which predict a Euler number that is relatively Reynolds number invariant above 10,000 . The experimental point at 10,000 is due to regions of flow through the cascade being in the laminar regime. This step change in Euler number, due to transition in the cascade flow from laminar to turbulent, has also been observed in other work by the authors [48.

\section{Conclusion}

A heat sink component has been developed for $\mathrm{HHF}$ applications in a near-term DEMO divertor. The design is composed of a number of laminate sheets that are individually machined and bonded together in a stack. This greatly facilitates manufacture and allows complex flow paths to be produced in a simplistic manor.

Water at 200 bar is employed as the coolant in a cascade jet impingement flow path arrangement. This method of deploying the flow allows increased pressure drop to be exchanged for a reduced mass flow rate. By operating the coolant in this manor the temperature change of the fluid can be increased, which can aid in improving the thermal cycle efficiency.

The general conclusions of the numerical modelling, and experimental validation, of the thermo-fluid performance of the HPJC-1a design are as follows:

- For DEMO relevant coolant inlet conditions the numerical results indicate that the design is capable of handling divertor target plate steady-state heat flux magnitudes;

- When compared at an equivalent heat flux, the HPJC1a was shown to have a reduced pumping power and mass flow rate in comparison to an ITER-like DEMO. This was for a matched value of the peak heat sink temperature minus the coolant inlet temperature;

- The CFD was validated against experiment by performing heat transfer and pressure drop measurements. The results of this comparison were as follows:

- The SST turbulence model correctly predicted the experimental area averaged convective heat transfer to within the measurement uncertainty of $9-13 \%$;

- Turbulence intensity was over predicted by the CFD in the secondary jet. The discrepancy was most pronounced at low Reynolds numbers;

- The stagnation point heat transfer levels were over predicted by the CFD by up to $60 \%$;

- The SST turbulence model provided the most accurate fit to the experimental convective heat 
transfer data, particularly at a local level around the stagnation point;

- Experimental heat transfer profiles were found to be flatter than those predicted by the CFD;

- All of the turbulence models failed to predict the transition from a laminar to turbulent boundary layer in the wall jet region, which was found in the experimental results;

- The experimental Euler number was 13\% above the CFD results. This was attributed to the uncertainty in the machined jet diameter.

\section{Acknowledgements}

The author gratefully acknowledges the support of the EPSRC, CCFE and Rolls-Royce as funders for this research.

\section{References}

[1] D. Maisonnier, I. Cook, P. Sardain, R. Andreani, L. D. Pace, R. Forrest, L. Giancarli, S. Hermsmeyer, P. Norajitra, N. Taylor, D. Ward, A Conceptual Study of Commercial Fusion Power Plants: Final Report of the European Fusion Power Plant Conceptual Study (PPCS), Tech. rep., EFDA (2005).

[2] D. Maisonnier, D. Campbell, I. Cook, L. D. Pace, L. Giancarli, J. Hayward, A. L. Puma, M. Medrano, P. Norajitra, M. Roccella, P. Sardain, M. Q. Tran, D. Ward, Power plant conceptual studies in Europe, Nuclear Fusion 47 (11) (2007) 1524.

[3] J. H. You, G. Mazzone, E. V. Et al, Conceptual Design Studies for the European DEMO Divertor: First Results, 12th International Symposium on Fusion Nuclear Technology.

[4] J. You, E. Visca, C. Bachmann, T. Barrett, F. Crescenzi, M. Fursdon, H. Greuner, D. Guilhem, P. Languille, M. Li, S. McIntosh, A. Müller, J. Reiser, M. Richou, M. Rieth, European DEMO divertor target: Operational requirements and material-design interface, Nuclear Materials and Energy 9 (2016) 171-176. doi:10.1016/j.nme.2016.02.005

[5] A. Herrmann, Overview on stationary and transient divertor heat loads, Plasma Physics Control and Fusion 44 (2002) 883903.

[6] J. Reiser, M. Rieth, Optimization and limitations of known DEMO divertor concepts, Fusion Engineering and Design 87 (56) (2012) 718-721.

[7] P. Norajitra, S. I. Abdel-Khalik, L. M. Giancarli, T. Ihli, G. Janeschitz, S. Malang, I. V. Mazul, P. Sardain, E. al., Divertor conceptual designs for a fusion power plant, Fusion Engineering and Design 83 (7-9) (2008) 893-902.

[8] T. B. W. T. S. M. D. H. M. Fursdon, Water-Cooled Divertor Target Design Study - Alternative CuCrZr Concepts, Tech. rep., EFDA - CCFE (2013).

[9] P. Norajitra, Divertor Development for a Future Fusion Power Plant, KIT Scientific Publishing, 2011.

[10] P. J. Karditsas, Optimization of the HETS He-Cooled Divertor Concept: Thermal Fluid and Structural Analysis, Fusion Science and Technology 47 (2005) 729-733.

[11] D. L. Youchison, M. T. North, J. E. Lindemuth, J. M. McDonald, T. J. Lutz, Thermal performance and flow instabilities in a multi-channel, helium-cooled, porous metal divertor module, Fusion Engineering and Design 49-50 (0) (2000) 407-415.

[12] C. Baxi, E. Chin, B. Laycock, W. Johnson, R. Junge, E. Reis, J. Smith, Design, Fabrication and Testing of Helium-Cooled Vanadium Module for Fusion Applications, in: Fusion Technology 1996, Elsevier, 1997, pp. 391-394. doi:10.1016/ B978-0-444-82762-3.50068-9
[13] L. Giancarli, J. P. Bonal, A. L. Puma, B. Michel, P. Sardain, J. F. Salavy, Conceptual design of a high temperature watercooled divertor for a fusion power reactor, Fusion Engineering and Design 75-79 (2005) 383-386.

[14] T. Ihli, A. R. Raffray, S. I. Abdel-Khalik, S. Shin, Design and performance study of the helium-cooled T-tube divertor concept, Fusion Engineering and Design 82 (2007) 249-264.

[15] M. S. Tillack, A. R. Raffray, X. Wang, S. Malang, Recent US activities on advanced He-cooled W-alloy divertor concepts for fusion power plants, Fusion Engineering and Design 86 (2010) 71-98.

[16] E. Visca, F. Crescenzi, A. Moriani, A. L. Puma, M. Richou, S. Roccella, Assessment of an ITER-like water-cooled divertor for DEMO, in: (SOFE), 2013 IEEE 25th Symposium on Fusion Engineering, 2013, pp. 1-6.

[17] M. Missirlian, M. Richou, B. Riccardi, P. Gavila, T. Loarer, S. Constans, The heat removal capability of actively cooled plasma-facing components for the ITER divertor, Physica Scripta (2011) 1-7.

[18] Heatric, General Heat Exchanger Overview Online (may 2013).

URL temp\{_\}pressure\{_\}capabilities.html

[19] J.-C. Han, Fundamental Gas Turbine Heat Transfer, Journal of Thermal Science and Engineering Applications 5 (2) (2013) 021007. doi:10.1115/1.4023826

[20] N. Zuckerman, N. Lior, Jet Impingement Heat Transfer: Physics, Correlations, and Numerical Modeling, Advances in Heat Transfer 39 (2006) 565-631.

[21] A. Pizzuto, P. J. Karditsas, C. Nardi, S. Papastergiou, HETS performances in He cooled power plant divertor, Fusion Engineering and Design 75-79 (2005) 481-484.

[22] B. Cheong, P. T. Ireland, A. Siebert, A cooling arrangement (dec 2005). URL http://www.google.com/patents/W02005117108A1?cl=en

[23] C. C. Land, C. Joe, K. A. Thole, Considerations of a DoubleWall Cooling Design to Reduce Sand Blockage, Journal of Turbomachinery 132 (3) (2010) 031011. doi:10.1115/1.3153308

[24] B. Weigand, S. Spring, B. Weig, S. Spring, Multiple Jet Impingement - A Review, Heat Transfer Research 42 (2) (2011) 101-142. doi:10.1615/HeatTransRes.v42.i2.30

[25] K. Jambunathan, E. Lai, M. A. Moss, B. L. Button, A review of heat transfer data for single circular jet impingement, International Journal of Heat and Fluid Flow 13 (1992) 106-115.

[26] F. P. Incropera, D. P. DeWitt, T. L. Bergman, A. S. Lavine, Fundamentals of Heat and Mass Transfer, 6th Edition, John Wiley and Sons Inc., 2007.

[27] S. J. Zinkle, Thermophysical and mechanical properties for Ta$8 \% \mathrm{~W}-2 \% \mathrm{Hf}$.

[28] 2.3.4. Explicit Algebraic Reynolds Stress Model URL https ://www. sharcnet.ca/Software/Ansys/17.0/en-us/ help/cfx\{_\}thry/thry\{_\}turb\{_\}earsm.html

[29] M. Behnia, S. Parneix, P. Durbin, Accurate modeling of impinging jet heat transfer, Tech. rep. (1997).

[30] Automatic Near-Wall Treatment for Omega-Based Models URL https://www.sharcnet.ca/Software/Ansys/16.2.3/ en-us/help/cfx\{_\}mod/i1346068.html

[31] J.-H. You, A review on two previous divertor target concepts for DEMO: mutual impact between structural design requirements and materials performance, Nuclear Fusion 55 (11) (2015) 113026. doi:10.1088/0029-5515/55/11/113026

[32] A. R. Raffray, J. Schlosser, M. Akiba, M. Araki, S. Chiocchio, D. Driemeyer, E. al., Critical heat flux analysis and R\&D for the design of the ITER divertor, Fusion Engineering and Design 45 (1999) 377-407.

[33] V. U. Kakade, G. D. Lock, M. Wilson, J. M. Owen, J. E. Mayhew, Accurate heat transfer measurements using thermochromic liquid crystal. Part 1: Calibration and characteristics of crystals, International Journal of Heat and Fluid Flow 30 (2009) 939-949.

[34] J. A. Stasiek, T. A. Kowalewski, Thermochromic liquid crys- 
tals applied for heat transfer research, Opto-Electronics Review 10 (1) (2002) 1-10.

[35] T. V. Jones, Z. Wang, P. T. Ireland, The use of liquid crystals in aerodynamic and heat transfer experiments, Procs Optical Methods and Data Processing in Health and FLuid Flow (1992) 51-65.

[36] P. T. Ireland, T. V. Jones, Liquid crystal measurements of heat transfer and surface shear stress, Measurement Science and Technology 11 (7) (2000) 969-986. doi:10.1088/0957-0233/11/ $7 / 313$

[37] M. McGilvary, D. Gillespie, Transient heat transfer analysis code for liquid crystal experiments at the University of Oxford: Updated GUI driven software, Tech. rep., University of Oxford (2011).

[38] R. J. Moffat, Contributions to the Theory of Single-Sample Uncertainty Analysis, Journal of Fluids Engineering 104 (1982) $250-258$.

[39] A. C. Chambers, An Investigation of Impingement Cooling Applied to Turbine Blade Cooling Passages, Ph.D. thesis, University of Oxford (2003).

[40] M. Shoukri, A. Calka, On the heat transfer characteristics of constrained air jets impinging on a flat surface, International Journal of Heat and Mass Transfer 30 (1) (1987) 203-205.

[41] L. Huang, M. El-Genk, Heat transfer of an impinging jet on a flat surface, International Journal of Heat and Mass Transfer 37 (1994) 1915-1923.

[42] N. T. Obot, W. J. M. Douglas, A. S. Mujumdar, Effect of semi-confinement on impingement heat transfer, Proceedings of the Seventh International Conference on Heat Transfer 3 (1982) 395-400.

[43] C. Son, P. Ireland, D. Gillespie, The Effect of Roughness Element Fillet Radii on the Heat Transfer Enhancement in an Impingement Cooling System, in: Volume 3: Turbo Expo 2005, Parts A and B, ASME, 2005, pp. 263-273. doi:10.1115/ GT2005-68186

[44] C.-Y. Li, S. V. Garimella, Prandtl-number effects and generalized correlations for confined and submerged jet impingement, International Journal of Heat and Mass Transfer 44 (18) (2001) 3471 - 3480. doi:http://dx.doi.org/10.1016/ S0017-9310(01) 00003-5

[45] D. R. H. Gillespie, S. M. Guo, Z. Wang, P. T. Ireland, S. T. Kohler, A Comparison of Full Surface Local Heat Transfer Coefficient and Flow Field Studies Beneath Sharp-Edged and Radiused Entry Impinging Jets, in: Volume 4: Heat Transfer; Electric Power; Industrial and Cogeneration, ASME, 1996, p. V004T09A047. doi:10.1115/96-GT-428

[46] C. Son, P. Ireland, D. Gillespie, The Effect of Roughness Element Fillet Radii on the Heat Transfer Enhancement in an Impingement Cooling System, in: Heat Transfer, ASME, 2005, pp. 263-273. doi:10.1115/GT2005-68186

[47] P. S. Penumadu, A. G. Rao, Numerical investigations of heat transfer and pressure drop characteristics in multiple jet impingement system, Applied Thermal Engineering 110 (2017) 1511-1524. doi:10.1016/J . APPLTHERMALENG. 2016.09.057

[48] J. R. Nicholas, P. T. Ireland, D. Hancock, D. Robertson, Manufacture and Initial Thermo-Fluid Measurements on a Heat Sink Module for Potential Applications in a DEMO, Fusion Science and Technology (2017) 1-8doi:10.1080/15361055.2017. 1350483 